\title{
Clinical Characteristics of Systemic Sclerosis With Interstitial Lung Disease
}

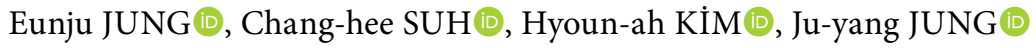 \\ Department of Rheumatology, Ajou University College of Medicine, Suwon, South Korea
}

\begin{abstract}
Objectives: This study aims to compare the clinical characteristics of systemic sclerosis (SSc) patients with or without interstitial lung disease (ILD), and figure out whether the differences can be useful to suspect ILD in SSc.

Patients and methods: We retrospectively collected the clinical data of 108 patients with SSC ( 13 males, 95 females; mean age $50.1 \pm 13.5$ years; range 14 to 78 years) and compared them according to the presence of ILD. ILD was confirmed by chest computed tomography, and pulmonary arterial hypertension was suspected when right ventricular systolic pressure was $\geq 40 \mathrm{mmHg}$ based on echocardiography.

Results: Of the 108 patients, 49 (45.4) had diffuse type and 59 (54.6) had limited type SSc. Disease duration, percentages of positive anti-scleroderma 70 (anti-Sc|70) antibody and anti-centromere antibody, white blood cell (WBC), platelet, erythrocyte sedimentation rate (ESR), and presence of pulmonary hypertension (PH) differed significantly. On multivariate logistic analysis, positive titer of anti-Scl70 antibody (odds ratio [OR] $=15.65$, $p<0.001)$, platelet $(O R=1.01, p=0.026), E S R(O R=1.02, p=0.037)$ and $P H(O R=21.97, p=0.003)$ were associated with ILD in patients with SSc.

Conclusion: In SSC patients with ILD, disease duration was longer and positive titer of anti-Scl70 antibody was more frequent, positive titer of anticentromere antibody was less frequent, and WBC and platelet counts, ESR levels, and incidence of possible PH were significantly higher than in those without ILD. Positive titer of anti-Scl70 antibody, platelet, ESR, and combination of PH were independently associated with the presence of ILD in SSc patients.

Keywords: Interstitial lung diseases; pulmonary hypertension; systemic sclerosis.
\end{abstract}

Systemic sclerosis (SSc) is a chronic connective tissue disease that causes systemic inflammation and fibrosis, damaging target organs such as skin, lungs, peripheral blood vessels, kidneys, heart, and the digestive system. ${ }^{1}$ Although its pathogenesis is complex and remains unclear, fibrosis is caused by vascular endothelial damage, immune activation, autoantibody formation, and excessive collagen and extracellular matrix production. ${ }^{2,3}$ The disease is three to eight times more common in females than in males, and occurs mainly in the fifth decade of life.$^{4,5} \mathrm{SSc}$ is divided into two subtypes according to the extent of skin involvement: a diffuse type involving the proximal limbs or trunk and a limited type involving the distal part limbs. ${ }^{6}$
Among the affected internal organs, respiratory involvement indicates a poor prognosis and is the common cause of death in patients with SSc. ${ }^{7}$ Respiratory involvement includes pulmonary arterial hypertension (PAH) and interstitial lung disease (ILD). Pulmonary involvement often develops in patients with a longer duration of SSc. ${ }^{8}$ However, this is controversial because the patients may not have any pulmonary symptoms during the early stage of the disease, and they develop typical symptoms such as dyspnea on exertion and cough only after the progression of lung fibrosis or PAH. Most of the data on SSc have been collected retrospectively, and might be biased for clinical reasons. ${ }^{9,10}$

Received: August 30, 2017 Accepted: November 20, 2017 Published online: January 15, 2018

Correspondence: Ju-yang Jung, MD. Department of Rheumatology, Ajou University College of Medicine, 16499 Suwon, South Korea. Tel: 82-31-219-5134 e-mail: serinne20@hanmail.net 
Although diverse mechanisms in the cellular and humoral pathway are involved in the pathophysiology of ILD and SSc, no drug can stop the progression of fibrosis or organ damage in SSc. An effective treatment to prevent this progression is needed, and substantial recent research has examined this. ${ }^{11}$ The presence of ILD in SSc patients determines the severity and expected prognosis of the disease and the early detection of pulmonary disease has been emphasized. Regular assessment has been recommended for ILD and PAH in SSc patients. ${ }^{12}$ To detect ILD earlier, regular pulmonary function testing (PFT) is suggested, including the diffusion capacity of the lungs for carbon monoxide and high-resolution computed tomography (HRCT). ${ }^{13,14}$ The severity of ILD in SSc ranges from limited involvement and non-progressive to severe and rapid progression, and also the symptoms are diverse. ${ }^{15}$ There is no distinct feature that patients with ILD might have, and as an initial and essential symptom, cough was identified to be less frequent and less severe in SSc-associated ILD compared to other fibrotic ILDs. ${ }^{16}$ Clinical assessment using HRCT showed good diagnostic performance for ILD in SSc. ${ }^{15}$ In this study, we aimed to compare the clinical characteristics of SSc patients with or without ILD, and figure out whether the differences can be useful to suspect ILD in SSc.

\section{PATIENTS AND METHODS}

The study included 108 patients with SSc (13 males, 95 females; mean age $50.1 \pm 13.5$ years; range 14 to 78 years) who were treated in the Ajou University Hospital Rheumatology Department between September 1999 and December 2015. The diagnosis of SSc was based on the 1980 American College of Rheumatology criteria for SSc. ${ }^{17}$ The study protocol was approved by the Ajou University Hospital Ethics Committee (BMR-SMP-16-387). The study was conducted in accordance with the principles of the Declaration of Helsinki.

Clinical records were collected retrospectively. The clinical features collected included SSc-related symptoms, such as Raynaud's phenomenon, scleroderma, skin ulcers, skin rashes, arthritis, and symptoms associated with the digestive system. Clinical examinations included chest radiography, chest computed tomography (CT), and echocardiography. Laboratory data comprised complete blood cell counts including white blood cells (WBCs), platelets, inflammatory markers, erythrocyte sedimentation rate (ESR) and $\mathrm{C}$-reactive protein (CRP). The presence and titers of autoantibodies, including antinuclear antibody (ANA), anti-scleroderma 70 (anti-Scl70) antibody, and anti-centromere antibody were gathered. The involvement of each organ was defined as

Table 1. Characteristics of patients with systemic sclerosis $(n=108)$

\begin{tabular}{|c|c|c|c|}
\hline & $\mathrm{n}$ & $\%$ & Mean \pm SD \\
\hline Age (year) & & & $50.1 \pm 13.5$ \\
\hline \multicolumn{4}{|l|}{ Gender } \\
\hline Female & 95 & & \\
\hline Male & 13 & & \\
\hline Duration (year) & & & $5.3 \pm 4.3$ \\
\hline \multicolumn{4}{|l|}{ Subtype } \\
\hline Diffuse & 49 & & \\
\hline Limited & 59 & & \\
\hline Positive antinuclear antibody & 104 & 96.3 & \\
\hline Anti-scleroderma 70 & 36 & 33.3 & \\
\hline Anti-centromere $\mathrm{Ab}$ & 42 & 38.9 & \\
\hline White blood cells $(\mu \mathrm{L})$ & & & $6944.5 \pm 2283.0$ \\
\hline Platelet $\left(\times 10^{3} / \mu \mathrm{L}\right)$ & & & $257.6 \pm 75.3$ \\
\hline Erythrocyte sedimentation rate $(\mathrm{mm} / \mathrm{h})$ & & & $31.6 \pm 24.9$ \\
\hline C-reactive protein (mg/dL) & & & $0.69 \pm 2.3$ \\
\hline Raynaud's phenomenon & 106 & 98.1 & \\
\hline Sclerodactyly & 97 & 89.8 & \\
\hline Skin rash & 28 & 25.9 & \\
\hline Digital ulcers & 27 & 25.0 & \\
\hline Arthritis & 57 & 52.8 & \\
\hline Gastrointestinal involvement & 44 & 40.7 & \\
\hline Interstitial lung disease & 43 & 39.8 & \\
\hline Pulmonary hypertension & 13 & 12.0 & \\
\hline
\end{tabular}


Table 2. Comparison of systemic sclerosis patients with interstitial lung disease and those not

\begin{tabular}{|c|c|c|c|c|c|c|c|}
\hline \multirow[t]{2}{*}{ Clinical features } & \multicolumn{3}{|c|}{ SSc with ILD (n=43) } & \multicolumn{3}{|c|}{ SSc without ILD (n=65) } & \multirow[b]{2}{*}{$p$} \\
\hline & $\mathrm{n}$ & $\%$ & Mean \pm SD & $\mathrm{n}$ & $\%$ & Mean \pm SD & \\
\hline Age (year) & & & $51.34 \pm 14.55$ & & & $49.23 \pm 13.51$ & 0.49 \\
\hline Gender & & & & & & & 0.92 \\
\hline Female & 38 & & & 57 & & & \\
\hline Male & 5 & & & 8 & & & \\
\hline Duration (year) & & & $6.72 \pm 5.02$ & & & $4.28 \pm 3.50$ & $0.012^{*}$ \\
\hline Subtype & & & & & & & 0.33 \\
\hline Diffuse & 22 & & & 27 & & & \\
\hline Limited & 21 & & & 38 & & & \\
\hline Antinuclear antibody (+) & 42 & 97.7 & & 62 & 95.4 & & 0.54 \\
\hline Anti-scleroderma $70(+)$ & 27 & 62.8 & & 10 & 15.4 & & $<0.001$ \\
\hline Anti-centromere (+) & 4 & 9.3 & & 33 & 50.8 & & $<0.001$ \\
\hline White blood cells $(\mu \mathrm{L})$ & & & $7650.9 \pm 2656.2$ & & & $6469.0 \pm 1858.1$ & $0.022^{*}$ \\
\hline Platelet $\left(\times 10^{3} / \mu \mathrm{L}\right)$ & & & $282.1 \pm 81.7$ & & & $241.3 \pm 66.5$ & $0.007^{*}$ \\
\hline Erythrocyte sedimentation rate $(\mathrm{mm} / \mathrm{h})$ & & & $39.4 \pm 27.3$ & & & $26.5 \pm 22.0$ & $0.008^{*}$ \\
\hline C-reactive protein (mg/dL) & & & $1.2 \pm 3.1$ & & & $0.3 \pm 1.4$ & 0.1 \\
\hline Raynaud's phenomenon & 42 & 97.7 & & 64 & 98.5 & & 0.77 \\
\hline Sclerodactyly & 38 & 88.4 & & 59 & 90.8 & & 0.69 \\
\hline Skin rash & 11 & 25.6 & & 17 & 26.2 & & 0.95 \\
\hline Digital ulcer & 15 & 34.9 & & 12 & 17.9 & & 0.06 \\
\hline Arthritis & 23 & 53.5 & & 34 & 52.3 & & 0.91 \\
\hline Gastrointestinal involvement & 21 & 48.8 & & 23 & 35.4 & & 0.17 \\
\hline Pulmonary hypertension & 11 & 25.6 & & 2 & 3.1 & & $<0.001^{*}$ \\
\hline
\end{tabular}

follows: arthritis was defined as the presence of joint tenderness and swelling or arthritic changes on radiography of the musculoskeletal system. ILD was confirmed by chest CT, and PAH was suspected when right ventricular systolic pressure was $\geq 40 \mathrm{mmHg}$ based on echocardiography.

\section{Statistical analysis}

Patients with or without ILD were compared using the two sample t-test, Mann-Whitney nonparametric tests, and chi-square analysis for categorical variables. To identify associations between clinical factors and the development of ILD, we calculated Spearman's correlation coefficient. Two-sided p-values $<0.05$ were considered statistically significant. All calculations were performed using IBM SPSS Statistics version 22.0 software (IBM Corp., Armonk, NY, USA).

\section{RESULTS}

The mean duration of disease was $5.3 \pm 4.3$ years (Table 1). Of the patients, 49 (45.4\%)

Table 3. Logistic regression analysis of clinical features to interstitial lung disease in patients with systemic sclerosis

\begin{tabular}{|c|c|c|c|c|c|c|}
\hline & \multicolumn{2}{|c|}{ Univariate } & \multirow[b]{2}{*}{$p$} & \multicolumn{2}{|c|}{ Multivariate } & \multirow[b]{2}{*}{$p$} \\
\hline & OR & $95 \% \mathrm{CI}$ & & OR & $95 \% \mathrm{CI}$ & \\
\hline Duration & 1.14 & $1.04-1.25$ & $0.007^{*}$ & & NA & \\
\hline Anti-scleroderma 70 (+) & 4.99 & $1.85-13.43$ & $0.001^{*}$ & 15.65 & $4.59-52.79$ & $<0.001^{*}$ \\
\hline Anti-centromere (+) & 0.1 & $0.032-0.31$ & $<0.001^{*}$ & & NA & \\
\hline White blood cells & 1.00 & $1.00-1.00$ & $0.012^{*}$ & 1.00 & $1.00-1.00$ & 0.09 \\
\hline Platelet & 1.01 & $1.00-1.01$ & $0.01^{*}$ & 1.01 & $1.00-1.02$ & $0.026^{*}$ \\
\hline Erythrocyte sedimentation rate & 1.02 & $1.01-1.04$ & $0.01^{*}$ & 1.02 & $1.0-1.04$ & $0.037^{*}$ \\
\hline Digital ulcer & 2.37 & $0.98-5.74$ & 0.057 & & NA & \\
\hline Pulmonary hypertension & 10.83 & $2.26-51.82$ & $0.003^{*}$ & 21.97 & $2.9-166.41$ & $0.003^{*}$ \\
\hline
\end{tabular}


had diffuse SSc, 59 (54.6\%) had limited SSc, and 104 (96.3\%) were ANA-positive. ANA was speckled in 45 (40.9\%), homogenous in 19 (17.3\%), nucleolar in $16(14.5 \%)$, centromeric in $13(11.8 \%)$, and mixed in 12 (10.9\%). Thirty six patients $(33.3 \%)$ had positive titers of anti-Scl70 antibody, and 42 patients (38.9\%) had positive titers of anti-centromere antibody. Patients' manifestations included Raynaud's phenomenon in 106 (98.1\%), sclerodactyly in 97 (89.8\%), arthritis in 57 (52.8\%), gastrointestinal symptoms in $44(40.7 \%)$, skin rash in 28 (25.9\%), and digital ulcers in 27 (25.0\%) (Table 1). ILD developed in 43 patients $(39.8 \%)$ and pulmonary hypertension (PH) was suspected in 13 (12.0\%).

The duration of disease was significantly longer in SSc patients with ILD than in those without ILD $(6.72 \pm 5.02$ vs. $4.28 \pm 3.50$ years, $\mathrm{p}=0.009$ ) (Table 2). In SSc patients with ILD, more patients had positive titers of anti-Scl70 antibody (62.8 vs. $15.4 \%, \mathrm{p}<0.001)$ and less patients had positive titers of anti-centromere antibody (9.3 vs. $50.8 \%, \mathrm{p}<0.001$ ) compared to those without ILD. SSc patients with ILD had significantly higher WBC $(7,650.93 \pm 2,656.22$ vs. $6,468.96 \pm 1,858.12 / \mu \mathrm{L}, \mathrm{p}=0.022)$ and platelet $(282,100 \pm 81,730$ vs. $241,300 \pm 66,500 / \mu \mathrm{L}$, $\mathrm{p}=0.007)$ counts and ESR levels $(39.4 \pm 27.3$ vs. $26.5 \pm 22.0 \mathrm{~mm} /$ hour, $\mathrm{p}=0.008$ ) than those without ILD. Possible PAH was also more common in SSc patients with ILD $(25.6 \%$ vs. $3.1 \%$, $\mathrm{p}<0.001)$. Considering the subtypes of ILD, 21 patients had usual interstitial pneumonia (48.8\%), while 20 patients had non-specific interstitial pneumonia (46.5\%).

On univariate logistic analysis, disease duration (odds ratio $[\mathrm{OR}]=1.14, \mathrm{p}=0.007$ ), positive titer of anti-Scl70 antibody (OR=4.99, $\mathrm{p}=0.001)$, positive titer of anti-centromere antibody $(\mathrm{OR}=0.1$ $\mathrm{p}=0.007), \mathrm{WBC}(\mathrm{OR}=1.00, \mathrm{p}=0.012)$, platelet $(\mathrm{OR}=1.01, \mathrm{p}=0.01), \mathrm{ESR}(\mathrm{OR}=1.02, \mathrm{p}=0.01)$ and $\mathrm{PH}(\mathrm{OR}=10.83, \mathrm{p}=0.003)$ were associated with ILD in patients with SSc (Table 3). On multivariate logistic analysis, positive titer of antiScl70 antibody $(\mathrm{OR}=15.65, \mathrm{p}<0.001)$, platelet $(\mathrm{OR}=1.01, \mathrm{p}=0.026)$, ESR (OR=1.02, $\mathrm{p}=0.037)$, and $\mathrm{PH}(\mathrm{OR}=21.97, \mathrm{p}=0.003)$ were associated with ILD in patients with SSc.

\section{DISCUSSION}

In patients with SSc, pulmonary involvement is related to poor prognosis and it is important to diagnose ILD or PAH quickly to intervene. However, this detection is frequently delayed when cases develop gradually without symptoms such as dyspnea or cough and the typical findings in PFT or on chest radiography. ${ }^{13,14,18}$ This study investigated the clinical characteristics of patients with SSc accompanied by ILD to identify the parameters suggesting some clues in asymptomatic patients with SSc with ILD.

The incidence of ILD is higher in patients with the diffuse type of SSc than in those with the limited type of SSc. In 3,656 patients with SSc, the European Scleroderma Trials and Research group reported that the incidence of ILD was $53 \%$ in patients with diffuse type SSc and 35\% in patients with limited type. ${ }^{18}$ Our results for the incidence of ILD according to subtype were similar.

Pulmonary involvement was reported to be related with specific ethic, socioeconomic, and behavioral factors in SSc. ${ }^{19}$ Patients with SSc with accompanying cardiopulmonary disease had frequent significant abnormalities on nailfold videocapillaroscopy. ${ }^{20}$ This is consistent with the increased incidence of digital ulcers due to peripheral vascular abnormalities in patients with pulmonary involvement in our study. Therefore, clinicians should suspect pulmonary involvement if a patient with SSc has abnormal nailfold videocapillaroscopy patterns or digital ulcers. In a recent report about severity and outcome of ILD in SSc, neither subtype of SSc nor specificity of autoantibodies was associated with severity of ILD in SSc, but digital ulcer and PH were closely related with deterioration of diffusing capacity of the lungs for carbon monoxide in SSc patients with ILD. ${ }^{21}$

In this study, SSc patients with ILD had higher positive values of anti-Scl70 antibody and lower positive values of anti-centromere antibody compared to those without ILD, and positivity of anti-Scl70 antibody was an independent risk factor for ILD in SSc patients. In line with other studies demonstrating a strong association between antiScl70 antibody and ILD, we found similar results among Korean SSc patients. ${ }^{22,23}$ 
The SSc patients with ILD had blood cell counts and inflammatory marker levels that differed from those in patients without ILD. Our patients had no secondary infections such as pneumonia, but the WBC and ESR were significantly elevated in SSc patients with ILD compared to those without ILD. Therefore, increased WBC and ESR might represent chronic inflammation status in pulmonary tissue without infection. A large cohort showed that baseline CRP was correlated with shorter survival and decline in forced vital capacity in SSc patients with ILD. ${ }^{24}$ CRP is used commonly as other inflammatory markers including ESR, and such data represented circulating markers that might predict inflammation in lung interstitium. CRP level was elevated in patients with ILD in this study without a statistical power. Moreover, several pro-inflammatory cytokines were reported higher in ILD progression in SSc. ${ }^{25}$

Pulmonary arterial hypertension in SSc leads to right heart failure and mortality, although its correlation has not been reported. ${ }^{26}$ In our series, the incidence of $\mathrm{PAH}$ was significantly higher in SSc patients with ILD. As predictive factors for PAH, its incidence was higher in SSc patients with ILD. ${ }^{27}$ Conversely, another study reported no association between the severity of ILD and the right atrial pressure measured via right catheterization in SSc patients, suggesting that the pulmonary fibrotic changes in the ILD of SSc differ from those of the pulmonary vascular pathophysiology in $\mathrm{PAH} .{ }^{28}$ Clinically, combined $\mathrm{PAH}$ in SSc patients with ILD leads to a large difference in the prognosis compared to that in SSc patients with ILD only. ${ }^{29}$

This study is limited in that it was a crosssectional and retrospective study from a single center, resulting in enrolment of a small number of patients and a lack of data related with progression or survival of SSc. In addition, there was no data of right catheterization for $\mathrm{PH}$ and gastrointestinal involvement. Nevertheless, to our knowledge, it is the first to analyze the clinical data of patients with SSc with pulmonary involvement in South Korea, and it shows the differences of SSc patients with ILD for further evaluations regarding ILD.

In conclusion, we analyzed the characteristics of SSc patients with ILD, and found that SSc patients with ILD had longer disease duration, positive value of anti-Scl70 antibody more frequently, positive value of anti-centromere antibody less frequently, higher WBC and platelet counts and ESR compared to those without ILD. The incidence of probable PAH suspected by echocardiography was significantly higher in patients with ILD than those without ILD. After adjustment, positive anti-Scl70 antibody, platelet count, ESR, and the development $\mathrm{PH}$ were significantly associated with ILD in SSc patients.

\section{Declaration of conflicting interests}

The authors declared no conflicts of interest with respect to the authorship and/or publication of this article.

\section{Funding}

This work was supported by the faculty research fund of Ajou University School of Medicine and the Korea Health Technology R\&D Project through the Korea Health Industry Development Institute (KHIDI), funded by the Ministry of Health \& Welfare, Republic of Korea (grant number: HI14C1731 and HI16C0992).

\section{REFERENCES}

1. Jimenez SA, Hitraya E, Varga J. Pathogenesis of scleroderma. Collagen. Rheum Dis Clin North Am 1996;22:647-74.

2. Gabrielli A, Avvedimento EV, Krieg T. Scleroderma. N Engl J Med 2009;360:1989-2003.

3. Ruaro B, Smith V, Sulli A, Decuman S, Pizzorni $\mathrm{C}$, Cutolo M. Methods for the morphological and functional evaluation of microvascular damage in systemic sclerosis. Korean J Intern Med 2015;30:1-5.

4. Ranque B, Mouthon L. Geoepidemiology of systemic sclerosis. Autoimmun Rev 2010;9:311-8.

5. Barnes J, Mayes MD. Epidemiology of systemic sclerosis: incidence, prevalence, survival, risk factors, malignancy, and environmental triggers. Curr Opin Rheumatol 2012;24:165-70.

6. LeRoy EC, Black C, Fleischmajer R, Jablonska S, Krieg T, Medsger TA Jr, et al. Scleroderma (systemic sclerosis): classification, subsets and pathogenesis. J Rheumatol 1988;15:202-5.

7. Steen VD, Medsger TA. Changes in causes of death in systemic sclerosis, 1972-2002. Ann Rheum Dis 2007;66:940-4.

8. Morrisroe K, Stevens W, Sahhar J, Rabusa C, Nikpour M, Proudman S. Epidemiology and disease characteristics of systemic sclerosis-related pulmonary arterial hypertension: results from a real-life screening programme. Arthritis Res Ther 2017;19:42. 
9. Zuhur F, Zuhur SS, Zuhur C, Musellim B, Ongen G. Survival in progressive systemic sclerosis with pulmonary involvement: a single-center experience in Istanbul, Turkey. Rheumatol Int 2012;32:165561.

10. Proudman SM, Stevens WM, Sahhar J, Celermajer D. Pulmonary arterial hypertension in systemic sclerosis: the need for early detection and treatment. Intern Med J 2007;37:485-94.

11. Yasuoka H. Recent Treatments of Interstitial Lung Disease with Systemic Sclerosis. Clin Med Insights Circ Respir Pulm Med 2016;9:97-110.

12. Cappelli S, Bellando Randone S, Camiciottoli G, De Paulis A, Guiducci S, Matucci-Cerinic M. Interstitial lung disease in systemic sclerosis: where do we stand? Eur Respir Rev 2015;24:411-9.

13. Giacomelli R, Liakouli V, Berardicurti O, Ruscitti P, Di Benedetto P, Carubbi F, et al. Interstitial lung disease in systemic sclerosis: current and future treatment. Rheumatol Int 2017;37:853-63.

14. Goh NS, Desai SR, Veeraraghavan S, Hansell DM, Copley SJ, Maher TM, et al. Interstitial lung disease in systemic sclerosis: a simple staging system. Am J Respir Crit Care Med 2008;177:1248-54.

15. Hax V, Bredemeier M, Didonet Moro AL, Pavan TR, Vieira MV, Pitrez EH, et al. Clinical algorithms for the diagnosis and prognosis of interstitial lung disease in systemic sclerosis. Semin Arthritis Rheum 2017;47:228-34.

16. Cheng JZ, Wilcox PG, Glaspole I, Corte TJ, Murphy $\mathrm{D}$, Hague $\mathrm{CJ}$, et al. Cough is less common and less severe in systemic sclerosis-associated interstitial lung disease compared to other fibrotic interstitial lung diseases. Respirology 2017;22:1592-7.

17. Preliminary criteria for the classification of systemic sclerosis (scleroderma). Subcommittee for scleroderma criteria of the American Rheumatism Association Diagnostic and Therapeutic Criteria Committee. Arthritis Rheum 1980;23:581-90.

18. Walker UA, Tyndall A, Czirják L, Denton C, FargeBancel D, Kowal-Bielecka O, et al. Clinical risk assessment of organ manifestations in systemic sclerosis: a report from the EULAR Scleroderma Trials And Research group database. Ann Rheum Dis 2007;66:754-63.

19. McNearney TA, Reveille JD, Fischbach M, Friedman AW, Lisse JR, Goel N, et al. Pulmonary involvement in systemic sclerosis: associations with genetic, serologic, sociodemographic, and behavioral factors. Arthritis Rheum 2007;57:318-26.

20. Markusse IM, Meijs J, de Boer B, Bakker JA, Schippers HPC, Schouffoer AA, et al. Predicting cardiopulmonary involvement in patients with systemic sclerosis: complementary value of nailfold videocapillaroscopy patterns and diseasespecific autoantibodies. Rheumatology (Oxford) 2017;56:1081-8.

21. Le Gouellec N, Duhamel A, Perez T, Hachulla AL, Sobanski V, Faivre JB, et al. Predictors of lung function test severity and outcome in systemic sclerosis-associated interstitial lung disease. PLoS One 2017;12:e0181692.

22. Liaskos C, Marou E, Simopoulou T, Barmakoudi M, Efthymiou G, Scheper T, et al. Disease-related autoantibody profile in patients with systemic sclerosis. Autoimmunity 2017;50:414-21.

23. Graf SW, Hakendorf P, Lester S, Patterson K, Walker JG, Smith MD, et al. South Australian Scleroderma Register: autoantibodies as predictive biomarkers of phenotype and outcome. Int $\mathrm{J}$ Rheum Dis 2012;15:102-9.

24. Liu X, Mayes MD, Pedroza C, Draeger HT, Gonzalez $\mathrm{EB}$, Harper $\mathrm{BE}$, et al. Does C-reactive protein predict the long-term progression of interstitial lung disease and survival in patients with early systemic sclerosis? Arthritis Care Res (Hoboken) 2013;65:1375-80.

25. Wu M, Baron M, Pedroza C, Salazar GA, Ying J, Charles $\mathrm{J}$, et al. CCL2 in the Circulation Predicts Long-Term Progression of Interstitial Lung Disease in Patients With Early Systemic Sclerosis: Data From Two Independent Cohorts. Arthritis Rheumatol 2017;69:1871-8.

26. Humbert M, Yaici A, de Groote P, Montani D, Sitbon $\mathrm{O}$, Launay $\mathrm{D}$, et al. Screening for pulmonary arterial hypertension in patients with systemic sclerosis: clinical characteristics at diagnosis and long-term survival. Arthritis Rheum 2011;63:3522-30.

27. Morrisroe K, Huq M, Stevens W, Rabusa C, Proudman SM, Nikpour M. Risk factors for development of pulmonary arterial hypertension in Australian systemic sclerosis patients: results from a large multicenter cohort study. BMC Pulm Med 2016;16:134.

28. Fischer A, Swigris JJ, Bolster MB, Chung L, Csuka ME, Domsic R, et al. Pulmonary hypertension and interstitial lung disease within PHAROS: impact of extent of fibrosis and pulmonary physiology on cardiac haemodynamic parameters. Clin Exp Rheumatol 2014;32:109-14.

29. Mathai SC, Hummers LK, Champion HC, Wigley FM, Zaiman A, Hassoun PM, et al. Survival in pulmonary hypertension associated with the scleroderma spectrum of diseases: impact of interstitial lung disease. Arthritis Rheum 2009;60:569-77. 